\title{
A Study on the Construction of High-Quality IT Majors in Higher Vocational Colleges
}

\section{—Based on the Sydney Agreement}

\author{
Zheng Liu \\ Suzhou Industrial Park Institute of Services Outsourcing \\ (SISO) \\ Suzhou, China \\ liuz@siso.edu.cn
}

\author{
Yuan Zhu \\ Suzhou Industrial Park Institute of Services Outsourcing \\ (SISO) \\ Suzhou, China \\ zhuyuan@siso.edu.cn
}

\author{
Shufeng Zhang \\ Suzhou Industrial Park Institute of Services Outsourcing (SISO) \\ Suzhou, China \\ Zhangshuf@siso.edu.cn
}

\begin{abstract}
The Sydney agreement is an international certification in terms of engineering and technical education designed for those who accept three years' higher education. Although China has not yet joined the agreement, by studying the international standards of engineering and technical talents and the paradigm of program construction, exploring the essence of Sydney agreement, combining the characteristics of majors and working out a program designed for majors, a featured goal can be achieved: constructing high-quality majors centered on students, oriented in results and with constant improvement, thereby self-correcting and continuously improving so as to realize the standardization and internationalization in cultivating students.
\end{abstract}

Keywords-the Sydney agreement; IT majors in higher vocational colleges; the paradigm of program construction; student-centered; result-oriented

\section{INTRODUCTION}

The "13th Five-Year Period" is an important stage of developing nationally vocational education, and promoting the development and reform of higher education. According to "Several Opinions on Deepening the Reform of Higher Education and Enhancing the Comprehensive Quality of Personnel Training"(File 6, Faculty 2015), and "Action Plan for Innovation and Development of Higher Education(20152018)" ,the scale of higher vocational education in China has developed rapidly, but the quality cannot fully meet the social demands for engineering and technical talents, which also reflects the ongoing road that higher vocational education has to proceed.

In this paper, the research was sponsored by the Advanced Training for Professional Major Leaders of Higher Vocational Colleges in Jiangsu Province (2017GRGDYX058), Cyan Engineering in Jiangsu Province, 3rd Education Reform Project of Vocational Colleges in Jiangsu Province (ZYB276).

\section{THE INTERNAL DEMANDS OF BUILDING UP HIGH-QUALITY MAJORS IN IT FIELD}

The construction of IT majors(groups) in Higher Vocational Education in Jiangsu Province has been in the relatively leading position. Among 230 high-quality majors set up in 2017 in Jiangsu Province, IT accounts for more than $20 \%$. Take the example of the vocational institute--Suzhou Industrial Park Institute of Services Outsourcing where the author works, 3 information technology specialties that cover 3 years of construction have been approved. This approval has acknowledged our previous professional construction work and affirmed that the faculty can effectively and timely handle the current changes in the process of professional construction. Those changes are as follows: the change in terms of characteristics among a new generation of young students, the change of individual career development, the change of individual learning methods and the strategy of how to cultivate students' adaptability to future development and sustainable competitiveness. That is to say, it is high time to reconsider and think deeply of the connotation and standardization of professional construction, the improvement of teaching and research ability, the construction of teaching staff and the improvement in the ability of social service.

The existing professional constructions, such as the making of training plans, the improvement of teaching modes, the teaching of professional qualities, and the requirements of graduates, most of which are still limited in drawing experience from domestic counterparts ${ }^{[1]}$. In terms of industryuniversity collaboration and work-integrated learning, foreign experience has been often referred, such as Germany and Singapore Model, but due to national and regional differences, few successful cases have been deeply studied and promoted. The problem facing China's higher vocational education now 
is to walk on a connotative developmental "road" where student-centered, result-oriented and professional construction is highly weighed, which is also the only way to construct higher vocational colleges with better qualifications. In this sense, the Sydney agreement is of great referring significance in the construction of information technology majors ${ }^{[2]}$.

The internationalization of higher vocational education has become an important strategy and policy for the development of Vocational Education in developed countries as well as in some developing countries. In our country, the higher vocational education is closely related to the social economy, so it will be an inevitable choice to take the road of internationalization and to implement the standardized professional certification.

At the national level, there is no unified and wide ranged certification designed for specific specialties at present. However, there have been certain requirements for the setting of majors so as to determine whether it can be allowed to set up. To a certain extent, there is a limit in the setting of majors and its setting must be within the scope of condition assessment, but it is not the same as the foreign professional certification. In the whole country, there are evaluation plans aiming at evaluating the whole training quality of personnel in higher vocational colleges--The Evaluation Plan of Talent Training in Higher Vocational Colleges. Some vocational schools are in collaboration with some certification education institutions, such as CEAC (Consular Electronic Application Center) and ATA (All American Online), and have launched a professional course accreditation teaching system. But this attempt is only a small pilot, which has not been widely spread.

For the certification of talent training in higher vocational colleges, students generally participate various vocational qualification certificates certified by the labor department. Such certificate is a required qualification for taking part in a particular job. Vocational qualification certificates have been highly valued by higher vocational colleges due to the recognition of employers. However, most of them are issued by labor departments in various provinces and cities; their degree of internationalization is not high. That is to say, the vocational qualification certificate obtained by Chinese students in higher vocational colleges cannot be recognized all over the world. This abuse is also one of the important reasons for the higher vocational colleges to participate in the international accreditation institutions such as the Sydney Agreement[3].

\section{THE ESSENCE AND REQUIREMENT OF SYDNEY AGREEMENT}

The Sydney Agreement specifies 7 aspects and focuses on students' training objectives, graduation requirements, teachers team construction, curriculum system and continuous improvement. The cultivation of students is the ultimate goal of professional construction, so we specifically study the relevant requirements from the aspects of the training and requirements of students.
A. The Sydney Agreement provides the requirements for the students' training objectives as follows[4]:

- Training objectives are bound to meet social needs: training objectives should be consistent with actual occupations, and should include professional working capabilities and core knowledge related to majors. At the same time, the training objectives should adapt to the needs of social and economic development.

- Curriculum design aims at the realization of training objectives : training objectives should provide relevant materials which can prove that professional courses can support the realization of training objectives, including the evaluation of core curriculum from graduates. At the same time, the curriculum design should certify that the skill knowledge is consistent with the core knowledge required in occupations.

- The evaluation and revision of training objectives: necessary rules and regulations should be established to periodically appraise the reached degree of training objectives, including feedback on the achievement of training objectives from students and society, periodic revision of the training objectives. The participation of students, enterprises or industry experts should be involved in the evaluation and revision process. The follow-up evaluation should be covered in the identity of students' profession.

\section{B. The Sydney Agreement has formulated the requirements for students as follows:}

- The system and measurements which are intended to attract excellent students should be specified in the setting of majors.

- Measurements such as learning guidance, career planning, employment guidance, psychological guidance should be specified and well implemented.

- The tracking and assessment of students’ performance in the learning process should be conducted so as to ensure that students meet graduation requirements when graduating, and that students have the ability to adapt to society and possess employment competitiveness after graduation, thereby meeting the requirements of training objectives. The recording process of evaluation and effect should be provided to certify that students have acquired certain skills.

\section{RESEARCH ON THE CONSTRUCTION OF IT SPECIALTY}

In general, the Sydney agreement has not only put forward the specific standards of certification, but also pointed out how to construct specialties in colleges and universities under the guidance of these standards. The basic guiding ideology of "Sydney Agreement" is to continuously improve and establish the basic bottom line of cultivating talents in higher engineering education with internationally recognized standards, which emphasizes the existing problems - only focus on meeting the get-by standard instead of being superior $^{[5]}$. Through the specific analysis of the accreditation 
standard, colleges and universities should make it clear that the construction of majors must start from the idea of system engineering, then find out the problems from several aspects of the certification standard, and finally formulate effective solutions to carry out the construction and implementation. The key is to refine its ideology and form a "paradigm" for professional construction. In conclusion, the model of professional construction embodied in the Sydney Agreement includes the following points:

\section{A. Student-centered}

The "student - centered" educational reform is a paradigm shift that must be promoted in a comprehensive, integrated and coordinated way. First of all, we should transform the concept of education--shift from teaching-centered to learning-centered. Meanwhile, we should set up teaching objectives, teaching contents and teaching methods so as to serve the training and cultivation of students. The evaluation of teaching should also focus on the indicators that can reflect the students' learning state and the effect of learning. It is necessary to take all the students into account.

\section{B. Result-oriented}

The result-oriented professional development requires a professional and comprehensive evaluation system, and multidimensional and sustainable assessment of students, majors and schools. Multi-dimensional assessment can ensure the objectivity, comprehensiveness and effectiveness of evaluation results. On the one hand, we should test the existing achievements of professional construction, and on the other hand, we will point out directions for future reforms. At the same time, the sustainable process assessment and the whole course tracking are the important guarantee for the continuous development and improvement of majors. Through the establishment of evaluation system, professional inspection of educational goals can be integrated with the market, and we can also examine whether professional courses and teaching goals can be achieved.

\section{Advocating Continuous Improvement}

In the past teaching process, the static and solo quality assurance system was emphasized, but the accreditation system of engineering, such as Sydney Agreement, is promoted with a dynamic, open and continuous improvement. Only by constant feedback and evaluation of the effect of education and teaching, the teaching links which need improving can be found and timely revised. Meanwhile, the maintenance and improvement of training quality can be guaranteed. By means of establishing a sound and continuous improvement system, reflecting on the quality requirements of training objectives and implementing the system steadily, we can truly promote the connotative development of specialty construction.

\section{Respect for Professionalized Personality}

The professional accreditation standards of formulating the Sydney Agreement focus on the establishment of training objectives and the setting up of curriculum system, but these are only the frameworks and guidelines of implementing professions, because there is still ample development space for educational process itself. The accreditation standards refer to the concept of the major fields and they divide the scope of professional certifications, but they do not interfere with specific professional settings. The classification of majors, and the accreditation that is in accordance with the same set of certification standards, fully respect the autonomy of setting up majors in colleges or universities. Meanwhile, the classification and accreditation can support the individual characteristics of each major, which contribute to setting individual development strategies that can integrate the needs of the market with the professional conditions of various colleges or universities.

\section{CONCLUSION AND DiRECTION OF ACTION}

How to draw experience from the Sydney Agreement to implement the construction of information technology majors in higher vocational education? Judge from the above analysis, the author believes that the key lies in how to integrate related standards and requirements. The background of the Sydney Agreement, the main content of the accreditation standard as well as the paradigm embodied in the professional construction are of great significance for China's current higher vocational education. Every college or university must firstly define the position of itself and its specialty, and then according to its own characteristics, reference standards and requirements, transform its standards and requirements into action plan. Based on the paradigm of constructing majors, it is wise, in the process of setting up majors and constructing majors with the basis of courses, to set the training objectives and graduation requirements, formulate the curriculum system and implement the relevant training requirements ${ }^{[6]}$. Construct high-quality majors that are students--centered, results--oriented and constantly improved, which paves way for self-correcting and continuously improving, thereby realizing the standardization and internationalization in cultivating students.

\section{REFERENCES}

[1] Jian lin, "How to understand and solve complicated engineering problems-based on the definition and requirement of Washington Agreement,” Education Research of Advanced Engineering, pp. 17-26, May 2016.

[2] Boqing Wang, "Implement Major Construction in Higher Vocational Colleges,” Education in Jiangsu Province, pp. 16-19, July 2014.

[3] Naifu Zhou, Research on Curriculum Construction-based on Sydney Agreement,” Fujian Computer , pp. 158-159, September 2016.

[4] Qiongge Zheng, Cixian Liu, and Zhengling Tang, "Graduates Qualities Set in Sydney Agreement and the inspiration to cultivate engineering talents," Education Research of Advanced Engineering, pp. 136-140, April 2016.

[5] Xuwei Huang, and Min $\mathrm{Hu}$, “A study of constructing an educational mode with library information-based on Sydney Agreement,” Library Theory and Practice, September 2017.

[6] Hongmei Gao, "A study of cooperative mode between schools and enterprises under the perspective of mutual benefit,” Master's Thesis in Hubei Normal University, 2012(11). 